\title{
$y_{\text {Rizoma }}=-\frac{00}{2}$ Biopolítica da criatividade: atenção, indeterminação e participação
}

\section{Resumo}

O presente ensaio estabelece vínculos entre os conceitos de atenção e de margem de indeterminação, tal como formulado na filosofia de Gilbert Simondon. Tais vínculos são aqui costurados a partir da ideia de cognição inventiva. A partir deste solo conceitual, que privilegia a produção de diferença, investiga-se como os imperativos de criatividade articulados à teoria neoliberal do capital humano constituem-se como uma nova faceta da biopolítica contemporânea.

Palavras-chave: Atenção; invenção; participação; Gilbert Simondon.

\section{Resumen}

Este ensayo establece vínculos entre los conceptos de atención y de margen de indeterminación, tal como fue formulado en la filosofía de Gilbert Simondon. Estos vínculos se construyen a partir de la idea de cognición inventiva. Desde esta base conceptual, centrada en la producción de diferencia, se investigó cómo los imperativos por creatividad, articulados a la teoría neoliberal del capital humano, constituyen una nueva faceta de la biopolítica contemporánea.

Palabras claves: Atención; invención; participación; Gilbert Simondon.
Icaro Ferraz Vidal Junior ${ }^{1}$

\begin{abstract}
${ }^{1}$ Graduado em Estudos de Mídia pela Universidade Federal Fluminense, mestre em Comunicação e Cultura pela Universidade Federal do Rio de Janeiro e em "Crossways in European Humanities" pelas Universidade Nova de Lisboa, Universidade de Santiago de Compostela e University of Sheffield. Atualmente realiza pesquisa no Programa "Erasmus Mundus Joint Doctorate: Cultural Studies in Literary Interzones", nas Università degli studi di Bergamo e Université de Perpignan Via Domitia.
\end{abstract}

\begin{abstract}
This essay proposes to establish links between the concepts of attention and margin of uncertainty, as formulated in the philosophy of Gilbert Simondon. Such ties are articulated from the idea of inventive cognition. From this conceptual ground that favors the production of difference, it is investigated how the imperatives of creativity articulated to the neoliberal theory of human capital are formed as a new facet of contemporary biopolitics.
\end{abstract}

Keywords: Attention; invention; participation; Gilbert Simondon. 


\section{Introdução}

Partiremos da ideia de que a atenção é um processo necessariamente transdutivo, o que implicará uma margem de indeterminação nas relações dos sujeitos com o mundo (VIDAL JUNIOR, 2011). Isso culmina na concepção de um modo de subjetividade marcado por um elevado grau de incerteza que, por um lado, liberta do dogmatismo das verdades constituídas mas, por outro, gera uma angústia que, no confronto com as demandas da vida prática, tende a fragilizar este sujeito, colocando-o no centro de um conjunto de dispositivos que atuam justamente na redução e neutralização desta margem de indeterminação.

Para os fins de nosso argumento, é importante construir o vínculo entre atenção e indeterminação, o que faremos à luz do pensamento de Gilbert Simondon (1989), cuja leitura será tangenciada pelas teses de Virgínia Kastrup (2007) acerca do conceito de cognição inventiva. A abertura da cognição à invenção, em Kastrup, está vinculada à introdução, nos estudos da cognição, de duas noções que o cognitivismo negligencia: o tempo e o coletivo. Já os objetos técnicos de Simondon, pensados segundo uma lógica bastante mais complexa que o modelo de máquina automatizada nos moldes input-output, comparecem aqui para que não tenhamos que negligenciar os vínculos entre atenção e tecnologia, legados pela modernidade e reconfigurados na contemporaneidade.

Em um segundo movimento, traçamos, a partir do curso Nascimento da Biopolítica, ministrado por Michel Foucault, em 1978-1979, no Collège de France, um solo a partir do qual poderemos pensar na indeterminação inventiva da atenção ocupando o centro das disputas contemporâneas. Estas seriam motivadas pela capitalização das variações cognitivas consideradas criativas.

\section{Atenção, modernidade e guerra}

Há alguns indícios de que os vínculos entre atenção e tecnologia não podem ser ultrapassados por uma simples negação da metáfora informacional, que supõe uma relação com a percepção fora do tempo, como input. Em Suspensions of Perception, Jonathan Crary (2001) mostra que a atenção, em sua formulação moderna, foi estudada primeiramente nos termos de respostas a estímulos de origem maquínica, de natureza elétrica e conteúdo abstrato. Tais respostas, na medida em que consistiam em reações a estímulos controlados, foram passíveis de uma quantificação que era, em última instância, o modo de relação da psicologia experimental moderna com a atenção.

Assim, os processos atencionais foram modernamente formulados sobre uma base empírica, tendo sido alocados no intervalo entre determinadas quantidades de energia fornecida e o tempo de reação ou as qualidades no desempenho de certas tarefas. Desta gênese, Crary deriva sua tese de que não há uma neutralidade atemporal nos regimes atencionais, tal como ele identifica em outras faculdades (respirar ou dormir ${ }^{2}$, por exemplo). Trata-
${ }^{2}$ Atualmente, Crary investiga a disputa contemporânea em torno do sono, indicando que dormir também tem uma inscrição histórica. Cf. CRARY, Jonathan. 24/7 Late Capitalism and the Ends of Sleep. London: Verso, 2013. 
se, antes, de um comportamento inserido em uma estrutura sócio-histórica, portador de um conjunto de normas, e parte importante do ambiente tecnológico moderno (CRARY, 2001, p. 26-29).

Ao longo da história do estudo da atenção e de sua constituição como objeto, Crary identifica um período que vai de começos do século XX até a década de 1930, quando o tema da atenção desaparece do campo de problematização da psicologia que, nesta época, contava com a hegemonia das correntes behavioristas. Tal silenciamento da atenção interessa menos do que o que parece ter desencadeado seu retorno ao campo de estudos da psicologia. Tanto Crary quanto Gómez-Iñiguez et al. (1999), identificam um movimento de retorno aos estudos da atenção na década de 1940, vinculado a uma problemática técnica, política e imagética.

Com o desenrolar da Segunda Guerra Mundial, observou-se uma série de problemas com os controladores de radar (problemas deles, em termos clínicos; mas também problemas gerados por eles, em termos militares). Os longos períodos de exposição e espera diante de imagens que, mesmo na ausência de eventos atrativos, demandavam um elevado engajamento atencional, colocavam um problema de ordem prática às forças armadas, que contaram com o suporte das então re-emergentes abordagens da psicologia da atenção.

Tais correntes focaram seus esforços analíticos em uma modalidade atencional precisa, que ficou conhecida como atenção vigilante ou sustentada, definida como "um processo sustentado e alerta, por meio do qual a receptividade à entrada de informação pode ser aumentada no curto prazo por exemplo quando a chegada de um sinal requerendo ação é iminente - ou mantida no longo prazo - como quando uma tarefa que requer vigilância ou atenção sustentada está sendo realizada" (PARASURAMAN, 1984, p. 12$13)^{3}$. Tal variação da atenção articula-se a determinadas noções tecnológicas importantes como, por exemplo, a de memória de trabalho, um dos conceitos forjados no interior das ciências cognitivas que, embora exterior ao processo atencional propriamente dito, está na base de sua modalidade vigilante.

A noção de working memory (IZQUIERDO, 2002) é importada do vocabulário informático e designa uma memória extremamente curta, que mantém determinada experiência on-line (por exemplo, a primeira palavra de uma frase, até que esta seja dita integralmente), para que o organismo decida se vale a pena ou não produzir uma memória desta percepção ${ }^{4}$. A experiência dos controladores de radar na guerra, traduzida nos termos desta orientação dos saberes $p s i$, por consistir em uma constante varredura do campo da imagem, demandaria um extremo grau de eficácia deste tipo de memória, combinado a uma capacidade de manutenção do engajamento atencional em alerta constante, na medida em que tem de ser capaz de se intensificar em um curto intervalo de tempo (quando um evento/ameaça aparece, sem qualquer indicação prévia, na imagem).

A experiência dos controladores de radares nos anos 40 comparece aqui por colocar em xeque a perspectiva cognitivista que procura entender a atenção a partir da relação input-output. As evidentes limitações cognitivas
${ }^{3}$ Todas as traduções de citações extraídas de obras em inglês e francês são nossas.

${ }^{4}$ É interessante observar que Henri Bergson, em Matéria e memória (1999), responde ao problema que as ciências cognitivas e a neurocienciência computacional (Rolls, 2008) colocam, hoje, em termos informáticos. A memória de trabalho nada mais é do que aquilo que Bergson diagnosticou como a impossibilidade de que, de fato, exista um percepção pura. Para Bergson, na medida em que toda percepção ocorre no tempo, ela implicaria já um trabalho da memória. 
colocadas pela demanda por uma intensividade extensiva da atenção parecem indicar a falência da analogia homem-máquina, baseada nesta concepção simplista da técnica, que formula a ação do homem no mundo como reação a um estímulo.

Mas não é adotando a ideia de que a analogia tecnológica para a compreensão da experiência humana profanaria uma suposta superioridade da condição humana que daremos consistência a nosso gesto especulativo. Tal gesto consistirá, antes, na retomada de algumas teses de Gilbert Simondon (1989), para pleitear que, enquanto processo transdutivo, a atenção implica necessariamente uma margem de indeterminação e, neste sentido, as máquinas têm muito a nos dizer sobre quem/o que somos.

\section{Indeterminação e aperfeiçoamento técnico}

Já na introdução de Du mode d'existence des objets techniques, Gilbert Simondon identifica na cultura um movimento de defesa do homem contra a técnica. Tal movimento supõe fronteiras rígidas, e pensa os objetos técnicos como absolutamente desprovidos de realidade humana. De acordo com o filósofo:

A oposição erigida entre a cultura e a técnica, entre o homem e a máquina, é falsa e sem fundamento; ela só encobre ignorância ou ressentimento. Ela mascara, atrás de um humanismo fácil, uma realidade rica em esforços humanos e em forças naturais, e que constitui o mundo dos objetos técnicos, mediadores entre a natureza e o homem (SIMONDON, 1989, p. 9).

Dando sequência à apresentação dos argumentos que justificam $D u$ mode..., Simondon opõe o objeto estético, cujo ingresso no universo das significações encontra legitimidade na cultura, ao objeto técnico, que só encontra lugar no mundo, sem significação, da utilidade. $\mathrm{O}$ contexto proveniente deste rechaço da técnica pela cultura faz com que aqueles que entendem a significação dos objetos técnicos procurem justificá-la à margem do estatuto que valora o objeto estético e, assim, conferem à técnica o estatuto de objeto sagrado. Gera-se, deste modo, uma idolatria que culmina em uma identificação do homem com a máquina, tangenciada por uma aspiração tecnocrática ao poder incondicional, que Simondon (1989, p. 10) desdobra nos seguintes termos:

O desejo de potência consagra a máquina como meio de supremacia, e faz dela o encantamento moderno. O homem que quer dominar estes semelhantes suscita a máquina androide. Ele abdica então diante dela e lhe delega sua humanidade. Ele procura construir a máquina pensante, sonhando poder construir a máquina desejante, a máquina vivente, para permanecer detrás dela sem angústia, liberado de todo perigo, imune a todo sentimento de debilidade, e triunfante mediatamente porque ele a inventou. Então, neste caso, a máquina tornou-se, segundo a imaginação, 

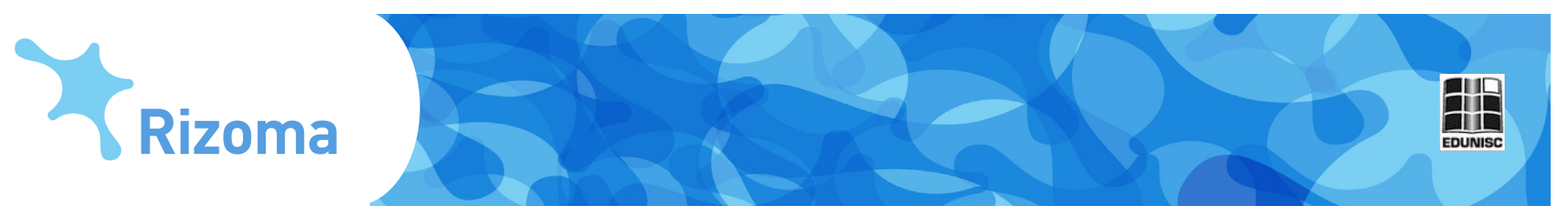

este duplo do homem que é o robô, desprovido de interioridade, representa de modo bem evidente e inevitável um ser puramente mítico e imaginário.

Simondon fornece uma interessante pista para que entendamos o que está em jogo nas leituras cognitivistas que abordam fenômenos complexos como a atenção, a partir dos pressupostos da teoria da informação. Ao percorrerem o caminho inverso ao que o filósofo indica no trecho citado, ou seja, ao predicarem o humano como processador de informação, conferindo-lhe atributos maquínicos, tais perspectivas asseguram ao humano a ausência de angústia, a liberdade diante do perigo e a eliminação do sentimento de debilidade. Mas trata-se, como no caso do robô, de um humano que é puramente mítico e imaginário.

Há, portanto, uma tensão no interior da cultura, na relação com os objetos técnicos: por um lado, Simondon (1989, p. 10-11) identifica a instauração de uma fronteira que separa humano e objetos técnicos, cabendo a estes uma existência esvaziada de significação, um tratamento como "puros aglomerados de matéria"; mas, por outro, há um movimento de atribuição de intenções hostis às máquinas com relação ao humano, por elas ameaçado. A partir desta tensão, Simondon introduz sua concepção de margem de indeterminação.

Esta contradição entre uma espécie de desprezo pelo objeto técnico como pura materialidade e uma idolatria pela máquina que pode, à semelhança do humano, portar atributos hostis, tem sua gênese, segundo Simondon (1989, p. 11), na ambiguidade das noções relativas ao automatismo.

Os idólatras da máquina apresentam em geral o grau de perfeição de uma máquina como proporcional ao grau de automatismo. Ultrapassando o que a experiência apresenta, eles supõem que, por um aumento e um aperfeiçoamento do automatismo chegaremos a reunir e a interconectar todas as máquinas entre elas, de maneira a constituir uma máquina de todas as máquinas.

Também podemos tentar traduzir a crença na proporcionalidade entre grau de automatismo e perfeição de uma máquina à luz daquela operação a que aludimos de atribuição de caracteres do maquínico ao humano. Formulamos esta suspeita a partir de $A$ invenção de si e do mundo: Um introdução do tempo e do coletivo no estudo da cognição, de Virgínia Kastrup (2007), obra que é desencadeada pela constatação da "inexistência de uma psicologia da invenção no domínio de estudos da cognição" (KASTRUP, 2007, p. 15). O que interessa reter das teses de Kastrup, neste ponto de nosso argumento, é que a consolidação do campo da psicologia operou em um registro similar à crença detectada por Gilbert Simondon como solo compartilhado tanto pelos que desprezam os objetos técnicos quanto pelos que o idolatram. A leitura de Simondon (1989, p. 11-12) da opinião corrente e compartilhada acerca do automatismo é a de que há aí uma falta lógica, pois,

O verdadeiro aperfeiçoamento das máquinas, aquele que podemos dizer que eleva o grau de tecnicidade, corresponde não a um aumento do automatismo, mas ao contrário ao fato de que o funcionamento de 

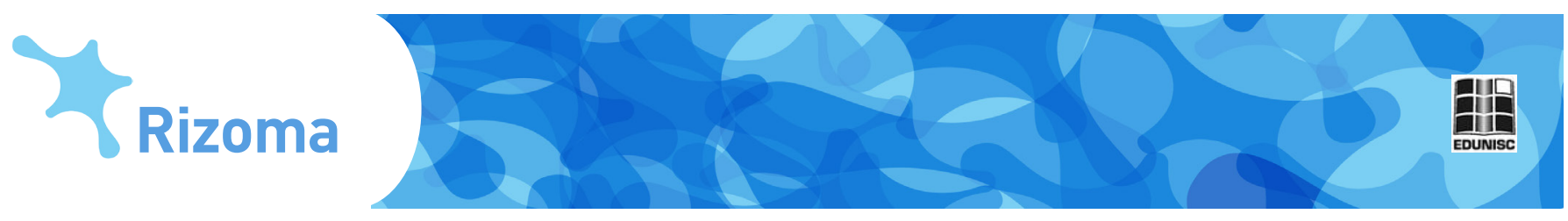

uma máquina esconde uma certa margem de indeterminação. É esta margem que permite à máquina ser sensível a uma informação exterior. É por esta sensibilidade das máquinas à informação que um conjunto técnico pode se realizar, bem mais que por um aumento do automatismo. Uma máquina puramente automática, completamente fechada sobre si mesma em um funcionamento pré-determinado, não poderia dar senão resultados sumários. A máquina que é dotada de uma alta tecnicidade é uma máquina aberta, e o conjunto das máquinas abertas supõe o homem como organizador permanente, como intérprete vivo das máquinas, umas em relação às outras.

Eis uma das formulações do conceito de margem de indeterminação, a partir do qual definimos a hipótese que está na base deste ensaio - que a atenção, sendo um processo inerentemente transdutivo, implica a abertura de um campo de indeterminação. Trata-se de uma noção que, oposta à de automatismo, configura um campo propício à invenção no interior dos agenciamentos maquínicos.

\section{Atenção, adaptação e risco}

O gesto que estamos realizando consiste, primeiramente, na recolocação da abordagem cognitivista da atenção. Tal abordagem apresenta uma série de limitações, cujas repercussões são imensas no âmbito da comunicação. Uma de suas limitações tem a ver com o pensamento da atenção em termos adaptativos. De acordo com Mialet (1999, p. 3), "a atenção é um fator essencial de adaptação do homem ao seu ambiente". Tal concepção implica uma relação de exterioridade e anterioridade entre homem e ambiente.

A perspectiva adaptativa acerca da atenção é sagazmente criticada no já mencionado trabalho de Virgínia Kastrup. Ao pensar a cognição como adaptação e resolução de problemas, a dimensão inventiva da cognição é negligenciada. Para chegar a esta asserção, Kastrup precisou diferenciar a criatividade da invenção. Esta diferença reside no fato de que a invenção supõe mais do que simplesmente a apresentação de uma nova resposta a um problema cognitivo previamente dado. A invenção investe a própria matriz cognitiva da experiência; ela é, sobretudo, invenção de problema. Já na ideia, cara ao cognitivismo, de adaptação, o ser, já pronto, só se relaciona com o ambiente a partir de um programa pré-definido que orienta a resolução de problemas. À margem desta concepção, o conceito de Kastrup de cognição inventiva introduz uma dimensão na qual sujeito e mundo inventam-se em um mesmo movimento.

Outra questão que orienta o cognitivismo é justamente o projeto de aniquilamento da margem de indeterminação dos processos cognitivos, em favor da automatização e da robotização, aspectos que, no plano dos objetos técnicos, Simondon já criticara. Embora isto seja reconhecidamente inalcançável, sua presença enquanto projeto pode ser diagnosticada no fragmento abaixo: 


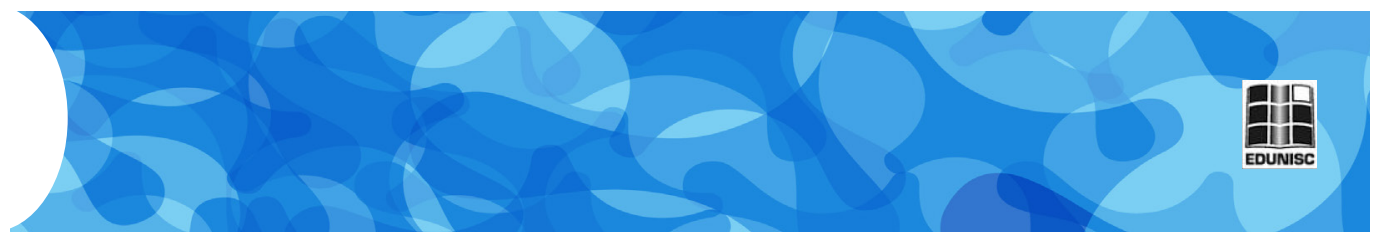

Em nossa época de automatização e de robotização, a realização de tarefas complexas tende a ser sistematicamente confiada às máquinas que, em uma situação dada, conseguem integrar mais parâmetros e se mostram mais precisas que qualquer operador humano. Estas máquinas não podem, no entanto, executar senão operações repetitivas; elas são incapazes de mostrar combinações inventivas. Diante do imprevisto, o homem resta necessário; sua atenção é então solicitada mais do que nunca, para controlar e vigiar os autômatos que ele desenvolveu. Contudo, suas habilidades parecem tornar-se cada vez mais secundárias.

Nossa sociedade não gosta do risco. Podemos prever que os erros humanos na vigilância de sistemas complexos, em relação com as flutuações naturais dos estados de atenção, ou com as modificações da atenção produzidas por fatores variados [...], serão minimizados pelos progressos realizados no conhecimento dos comportamentos atencionais. Eles não poderão, todavia, ser completamente erradicados. (MIALET, 1999, p. 3)

Curiosamente, termos presentes na filosofia da técnica simondoniana (automatismo, robotização, máquinas, combinações inventivas, risco) reaparecem no texto sobre atenção de Mialet, um psiquiatra. Tal fato está vinculado à questão que fez com que Virgínia Kastrup postulasse o problema da invenção no interior da psicologia a partir de uma história filosófica (e não de uma história). Nomeadamente, ao fato de que a psicologia configurouse atravessada por uma intencionalidade não subjetiva, inscrita no seio de demandas históricas instrumentalizantes, comprometidas com a formulação de sujeitos coesos, unidades idênticas a si próprias, condição de manutenção de uma determinada formação social disciplinar e industrial. Tal formulação da cognição, comprometida com a determinação e com o controle da experiência, não teria sido possível sem a eliminação do tempo, do corpo e do coletivo e, neste sentido, da invenção.

\section{Atenção e indeterminação sobre o solo econômico}

Mas, a repercussão deste movimento da psicologia cognitiva de negligência da invenção em um plano político-econômico parece-nos, em certo sentido, atravessada por uma tensão que precisa ser explorada. Para isto, partiremos do curso ministrado por Michel Foucault em 1978-1979 no Collège de France, intitulado Nascimento da Biopolítica (2008), derivando algumas consequências (bio)políticas do argumento que viemos construindo até aqui: o de que a atenção foi pensada e sofreu investimentos do poder no sentido da eliminação de sua margem de indeterminação, em favor de uma concepção do humano enquanto máquina simples ${ }^{5}$.

Esta conexão advém de uma antinomia, talvez ainda pouco evidente, entre, por um lado, uma noção da experiência atencional nos termos $A \rightarrow B$, que tangencia o projeto das sociedades disciplinares, cartografado por Foucault; e, por outro, um modelo "criativo" de atenção, incitado no interior dos regimes pós-disciplinares, e que tem suas bases nas variações do valor do trabalho humano. Dito de outro modo, à luz do ensaio de Gilles
${ }^{5}$ Simondon entende as máquinas simples como aquelas que são fechadas sobre si, através de um desenvolvido grau de automatismo. 
Deleuze (1992) a respeito das sociedades de controle, a tensão situa-se entre o desejo industrial-disciplinar de eliminação da indeterminação e da invenção, por elas constituírem um empecilho ao funcionamento azeitado dos dispositivos disciplinares; e as inflexões deste desejo no processo de crescente imaterialização do capitalismo. Tal processo é patente onde os investimentos do poder e do capital sobre a cognição inventiva já não se dão por uma negação, por um silenciamento, mas por um incessante gesto de captura, através da produção de criatividades reféns das alegrias do marketing.

Diante das formas assumidas pelo capitalismo contemporâneo, podemos arriscar dizer que o postulado cognitivista da atenção, ancorado nas noções invariantes de input e output, não faz tanto sentido no plano dos investimentos biopolíticos: trata-se de uma perspectiva anacrônica, mesmo se o horizonte adotado é o da sujeição. A seguir, retomaremos alguns argumentos de Michel Foucault comprometidos com a identificação disso que estamos formulando, à luz de Simondon, como a dimensão indeterminada da cognição na base do desenvolvimento da sociedade capitalista neoliberal.

\section{Repensando o trabalho}

$\mathrm{Na}$ aula de 14 de março de 1979, ao falar do neoliberalismo americano, Michel Foucault apresenta e desenvolve algumas ideias a partir da teoria do capital humano. Tal evocação, de acordo com Foucault, tem seu interesse justificado por representar dois processos, que ele define como sendo, por um lado, o que chamou de "incursão da análise econômica num campo até então inexplorado" (FOUCAULT, 2008, p. 302) e, por outro, uma possibilidade de reinterpretação em termos econômicos de todo um domínio que, até então, era considerado não-econômico.

Quanto à incursão da análise econômica em seu próprio domínio, Foucault (2008, p. 302-303) retoma o ponto no qual, segundo ele, tal análise havia ficado suspensa:

os neoliberais americanos dizem o seguinte: é estranho, a economia política clássica sempre indicou, e indicou solenemente, que a produção de bens dependia de três fatores: a terra, o capital e o trabalho. Ora, dizem eles, o trabalho sempre permaneceu inexplorado. Ele foi, de certo modo, a página em branco na qual os economistas não escreveram nada. [...] a economia política clássica nunca analisou o trabalho propriamente, ou antes, empenhou-se em neutralizá-lo, e em neutralizá-lo restringindo-o exclusivamente ao fator tempo [...]. Neutralização, por conseguinte, da própria natureza do trabalho, em benefício exclusivo dessa variável quantitativa de horas de trabalho e de tempo de trabalho.

Foucault observa aí um movimento, por parte dos neoliberais americanos, de reintrodução do trabalho no campo de análise econômica. O filósofo identifica ainda um estranho silêncio dos neoliberais com relação ao tratamento que Marx dá à noção de trabalho. $\mathrm{O}$ trabalho, em Marx, diriam 
os neoliberais, não é tematizado enquanto trabalho, mas somente enquanto força de trabalho. Marx pensa o trabalho como produção de valor, mas pensa esta produção de valor a partir da expropriação ao trabalhador, através da venda de uma parcela da força de trabalho. Com base nesta perspectiva, Marx vislumbra a lógica mesma do capitalismo:

o trabalho concreto transformado em força de trabalho, medido pelo tempo, posto no mercado e retribuído como salário não é o trabalho concreto; é um trabalho que está, ao contrário, amputado de toda a sua realidade humana, de todas as suas variáveis qualitativas, e justamente - é bem isso, de fato, o que Marx mostra - a mecânica econômica do capitalismo, a lógica do capital só retém do trabalho a força e o tempo. Faz dele um produto mercantil e só retém seus efeitos de valor produzido. (FOUCAULT, 2008, p. 305)

Segundo Foucault, a diferença entre Marx e os neoliberais, no que tange à "abstração" do trabalho consiste em que, para Marx, esta abstração seria gerada pelo próprio sistema capitalista, ao passo que os neoliberais só vislumbram tal abstração como parte de uma teoria econômica, não sendo tal processo concebido por eles como parte do capitalismo real. A mutação epistemológica articulada pelo neoliberalismo americano teria a ver, portanto, com o modo como se passa a conceber o objeto da análise econômica e, neste sentido, Foucault cita uma definição do economista inglês Lionel C. Robbins, que escreveu que "a economia é a ciência do comportamento humano, a ciência do comportamento humano como uma relação entre fins e meios raros que têm usos mutuamente excludentes" (FOUCAULT, 2008, p. 306). O que a análise econômica deve procurar elucidar, segundo esta perspectiva, são os cálculos que dão conta do porquê, diante da raridade dos recursos, um grupo de indivíduos decide atribuí-los a um determinado fim e não a outro.

À luz do projeto de chegada a um cálculo que permita antecipar eventos em um campo que iremos, na esteira das linhas gerais de nosso argumento, definir como indeterminado, os neoliberais chegam à introdução efetiva do trabalho no campo da análise econômica. Afastando-se das já mencionadas análises do "trabalho abstrato", os neoliberais defendem que:

O problema fundamental [...] que se colocará a partir do momento em que se pretenderá fazer a análise do trabalho em termos econômicos será saber como quem trabalha utiliza os recursos de que dispõe. Ou seja, será necessário, para introduzir o trabalho no campo da análise econômica, situar-se do ponto de vista de quem trabalha; será preciso estudar o trabalho como conduta econômica praticada, aplicada, racionalizada, calculada por quem trabalha. (FOUCAULT, 2008, p. 307)

A proposição dos neoliberais, diante da necessidade acima apresentada, é a de que nos instalemos, a fim de investigar o trabalho desde uma perspectiva econômica, no entendimento do trabalho desde a perspectiva do próprio trabalhador. E, neste caso, o trabalho não pode ser pensado como venda da força de trabalho pois, do ponto de vista do trabalhador, "o salário não é o 


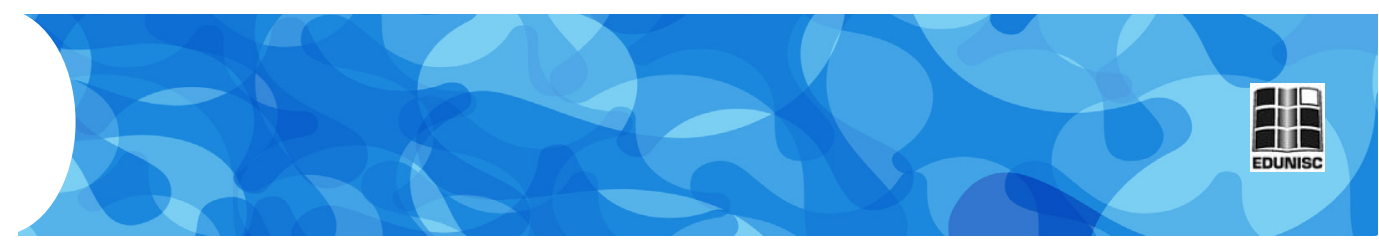

preço da venda da sua força de trabalho, é uma renda" (FOUCAULT, 2008, p. 308). E o que é uma renda? - Indaga Foucault, respondendo a seguir que os neoliberais adotam a ideia de que a renda é "o produto ou o rendimento de um capital" (FOUCAULT, 2008, p. 308).

$\mathrm{Na}$ sequência desta proposição, chega-se ao conceito de capital humano, central nas teses que Michel Foucault formula neste curso, nos desenvolvimentos contemporâneos do conceito de trabalho imaterial no âmbito do capitalismo cognitivo e, não menos central, em nosso empreendimento teórico de pensar as repercussões das diferentes concepções da atenção no contexto da biopolítica contemporânea. O trabalho humano é, dentro da abordagem neoliberal, composto de capital e de renda, sendo o capital "o conjunto de todos os fatores físicos e psicológicos que tornam uma pessoa capaz de ganhar este ou aquele salário, de sorte que, visto do lado dos trabalhadores, o trabalho não é uma mercadoria reduzida por abstração à força de trabalho e ao tempo [durante] o qual ela é utilizada" (FOUCAULT, 2008, p. 308).

A primeira implicação derivada desta decomposição entre capital e renda consiste em que este capital se torna indissociável daquele que o detém, do trabalhador, e, neste sentido, não se trata de um capital como os outros. Foucault (2008, p. 309) também recorre às máquinas para pensar nesta relação.

A competência do trabalhador é uma máquina, sim, mas uma máquina que não pode se separar do próprio trabalhador, o que não quer dizer exatamente, como a crítica econômica, ou sociológica, ou psicológica dizia tradicionalmente, que o capitalismo transforma o trabalhador em máquina e, por conseguinte, o aliena. Deve-se considerar que a competência que forma um todo com o trabalhador é, de certo modo, o lado pelo qual o trabalhador é uma máquina, mas uma máquina entendida no sentido positivo, pois é uma máquina que vai produzir fluxos de renda. Fluxos de renda, e não renda, porque a máquina constituída pela competência do trabalhador não é, de certo modo, vendida casualmente no mercado de trabalho por certo salário. Na verdade, essa máquina tem sua duração de vida, sua duração de utilizabilidade, tem sua obsolescência, tem seu envelhecimento. De modo que se deve considerar que a máquina constituída pela competência do trabalhador, a máquina constituída, digamos, por competência e trabalhador individualmente ligados vai, ao longo de um período de tempo, ser remunerada por uma série de salários que, para tomar o caso mais simples, vão começar sendo salários relativamente baixos no momento em que a máquina começa a ser utilizada, depois vão aumentar, depois vão diminuir com a obsolescência da própria máquina ou o envelhecimento do trabalhador na medida em que ele é máquina. Portanto há que considerar o conjunto como um complexo máquina/fluxo, dizem os neo-economistas.

A argúcia do economicismo neoliberal reside, segundo uma leitura a partir do solo conceitual que viemos sedimentando, na concepção da competência como máquina, mas como máquina aberta, produtora de fluxos. Trata-se de um gesto arguto pois, se na filosofia de Simondon esta noção serve à instauração de uma margem de indeterminação, que lemos como uma abertura à inovação, naquele sentido que encontramos em 
Kastrup; os desenvolvimentos da aula de Michel Foucault nos levarão a uma problematização da competência em termos similares àqueles nos quais as fronteiras entre invenção e criatividade foram colocados por Virgínia Kastrup, nomeadamente, o problema da instrumentalidade.

\section{Da articulação entre capital humano e inovação}

A análise neoliberal da decomposição do trabalho em capital e renda conduz à transformação dos trabalhadores em unidades-empresa. O que significa que a vida será objeto de uma gestão, organizada segundo uma racionalidade econômica. Tal racionalidade já é fruto de um deslocamento do homo oeconomicus enquanto parceiro de troca, para um homo oeconomicus que é empresário de si. Uma consequência deste processo desemboca no segundo nível anunciado por Michel Foucault no início de sua aula: com a introdução do conceito de capital humano, a análise econômica penetra âmbitos que, até então, encontravam-se fora de seu escopo.

Nesta direção, Foucault evoca a teoria do consumo formulada por Gary Becker, segundo a qual "o homem do consumo não é um dos termos da troca. O homem do consumo, na medida em que consome, é um produtor. Produz o quê? Pois bem, produz simplesmente sua própria satisfação" (FOUCAULT, 2008, p. 311). Talvez possamos acrescentar a este trecho, dando um salto no interior do pensamento de Foucault, que aquilo que o consumo gera passa a ser entendido também como produção de capital humano e, neste sentido, passa a ser investimento. A dimensão adquirida do capital humano (pois, segundo Foucault, há também uma dimensão inata, proveniente do capital genético) realiza-se, voluntária ou involuntariamente, no curso da vida dos indivíduos. Essa aquisição de capital humano passa pelos investimentos em educação, mas não se restringe a eles. Trata-se de algo mais abrangente. Podemos dizer que a totalidade das experiências que podem vir a aumentar a competência são entendidas na lógica neoliberal como aquisição de capital: incluem-se aí elementos que vão do tempo empregado pelos pais na criação dos filhos, na infância e no desenvolvimento de atividades extracurriculares, até determinadas experiências migratórias.

O interesse dessas análises, segundo Foucault, é simples e se justifica precisamente a partir da noção de inovação, que seria o conceito-chave para elucidar a continuidade e o progresso do capitalismo a despeito do que, no linguajar econômico, convencionou-se chamar de uma baixa tendencial da taxa de lucro. O problema da constante correção desta baixa tendencial da taxa de lucro foi pensado pela economia clássica a partir dos termos que constituíam seu escopo de análise: as articulações de terra, capital e trabalho. O imperialismo, por exemplo, explicaria a correção desta baixa tendencial pela descoberta de novas fontes de capital, terra e trabalho (mão de obra pensada quantitativamente). Mas os neoliberais colocaram o problema da inovação em outros termos: 


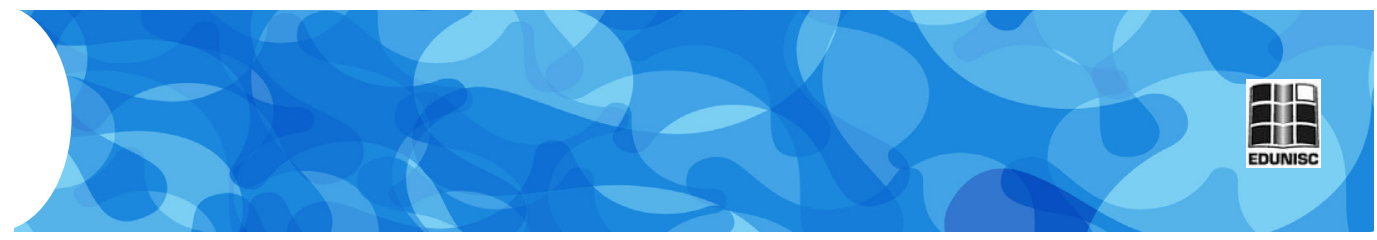

\begin{abstract}
Se inovação existe, isto é, se se encontram coisas novas, se se descobrem formas novas de produtividade, se se fazem invenções de tipo tecnológico, tudo isso nada mais é que a renda de um certo capital, o capital humano, isto é, o conjunto dos investimentos que foram feitos no nível do próprio homem. E, retomando assim o problema da inovação no interior da teoria mais geral do capital humano, eles procuram mostrar [...] que o crescimento [...] não pode ser em absoluto explicado simplesmente [a partir] das variáveis da análise clássica, isto é, a terra, o capital e o trabalho, entendido como tempo de trabalho, isto é, em número de trabalhadores e em número de horas. Só uma análise fina da composição do capital humano, da maneira como esse capital humano foi aumentado, dos setores nos quais ele foi aumentado e dos elementos que foram introduzidos a título de investimento nesse capital humano, é somente isso que pode explicar o crescimento efetivo. (FOUCAULT, 2008, p. 318-319)
\end{abstract}

\title{
7 Criatividade subserviente
}

O conceito de capital humano ajuda-nos a compreender o solo políticoeconômico que sustenta o investimento contemporâneo na criatividade. Aqui, evocamos novamente a distinção estabelecida por Virgínia Kastrup entre criatividade e invenção. A autora parte da inviabilidade de uma história da invenção no interior da psicologia, por esta noção nunca ter aparecido nos estudos da cognição, para então estabelecer algumas nuances na relação entre sua ideia de invenção e outros conceitos, que foram previamente tematizados no interior da psicologia e que, pelo uso corrente das palavras que os designam, poderiam gerar algum mal entendido. Um desses conceitos é o de criatividade, que aparece na literatura psicológica a partir da década de 1950 e adquire grande visibilidade nos anos 1960 e 1970, sobretudo nos Estados Unidos.

A noção de criatividade é formulada por trabalhos de vertente técnica ou psicométrica, não como um talento raro e excepcional, tal como está implícito no conceito de gênio, mas como "uma capacidade ou função de criação, distribuída, até certo ponto, por todos os seres humanos" (KASTRUP, 2007, p.17). Ainda de acordo com Kastrup (2007, p. 18),

são as exigências da sociedade americana que movem tais trabalhos. Para a corrida espacial, para a indústria e a propaganda, cumpre selecionar indivíduos criativos. Daí também o desenvolvimento de inúmeras técnicas para a estimulação e mesmo para o treinamento da criatividade, a serem empregadas em espaços diversos, como instituições governamentais, escritórios, escolas, etc. Toda uma tecnologia voltada para a educação e para a administração de empresas é criada com vistas à maximização dos desempenhos originais.

A autora sublinha que o aparente contrassenso presente na concepção de um treinamento da criatividade pode ser esclarecido ao se atentar para o modo como o problema da criatividade é formulado. A criatividade não é entendida por tais estudos como uma função independente, mas sim como uma parte da inteligência, que é definida como "uma capacidade múltipla de lidar com problemas". Apesar da inconsistência que esta formulação da criatividade apresenta, o que 
merece destaque é que tais estudos postulam a criatividade sob uma perspectiva instrumental. A criatividade é equacionada com a ideia de desempenho, sendo postulada em uma condição de subserviência à solução de problemas (domínio da inteligência) e consistindo em um mero fator de divergência em relação a soluções habituais. A esta formulação da criatividade, Kastrup (2007, p. 19), evocando o pensamento de Henri Bergson, responde que

um problema está mal colocado quando sua formulação indica que se está trabalhando com um misto mal analisado. No caso, é a noção de criatividade mistura dessas duas tendências que, segundo Bergson, diferem em natureza. Por um lado, ela é definida como função de criação; por outro, como solução de problemas. A criação encontra-se, então, a serviço de problemas já dados, que são, em última análise, os da sociedade, principalmente da sociedade americana.

\section{Considerações finais}

É na esteira desta consideração de Kastrup que, para finalizar, lançaremos nossa suspeita com relação a uma série de discursos que celebram as reconfigurações da paisagem midiática contemporânea, promovidas pelos desenvolvimentos da rede mundial de computadores, como sendo, em si mesmas, promotoras de uma liberação que é pensada a partir de uma descentralização institucional e da proliferação dos mitos sobre participação. O conceito de biopolítica parece ser uma via interessante de aproximação ao que parece estar em jogo neste contexto.

Se, à crítica da cultura de massa, o conceito de ideologia parecia caber como uma "luva", na medida em que os espectadores/ouvintes/leitores supostamente incorporavam o sistema de crenças e valores da esfera produtora sem se darem conta do lugar de suposta passividade que lhes cabia no interior do dispositivo; a introdução da participação como imperativo no capitalismo 2.0 parece lançar novos desafios à crítica da comunicação e da cultura. Ao suspeitarmos da crença na abolição de um polo privilegiado na difusão cultural, supostamente propiciada pelas redes, chegamos à hipótese de que na biopolítica, o que se incute no espectador não é um conteúdo ideológico, mas um modelo cognitivo, comprometido com a criatividade não com a invenção -, na medida em que é fixado por práticas, cada vez mais difusas socialmente, de trânsito rápido, eficaz, vigilante e participativo entre várias interfaces.

Com o desenvolvimento da noção de capital humano na gênese de uma biopolítica da criatividade, a experiência midiática passa a ser compreendida como produção de capital, e os investimentos do poder neste âmbito excedem a simples quantificação do tempo de exibição a ser capitalizado através da venda de anúncios publicitários, de ideias, de projetos políticos, etc. Se há uma relação entre poder e mídia que nos interessa formular com a finalidade de relacionar atenção, indeterminação e biopolítica, esta relação consiste em um modo produtivo, de incitação à atividade criativa incessante. 

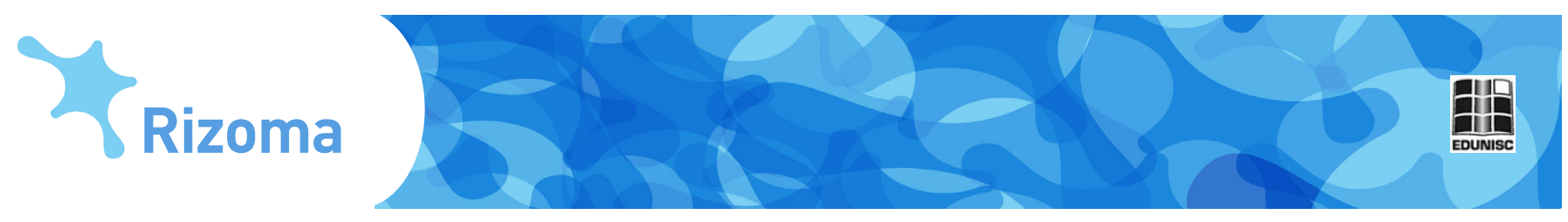

Atividade esta que reforça a matriz cognitiva já instituída e procura manter a radicalidade de uma efetiva margem de indeterminação fora do terreno do pensável e do vivível.

\section{Referências:}

BERGSON, Henri. Matéria e memória: ensaio sobre a relação do corpo com o espírito. São Paulo: Martins Fontes, 1999.

CRARY, Jonathan. Suspensions of Perception: Attention, Spectacle and Modern Culture. London/Massachusetts: MIT Press, 2001.

DELEUZE, Gilles. Conversações, 1972-1990. São Paulo: Ed. 34, 1992.

FOUCAULT, Michel. Nascimento da biopolítica: curso dado no Collège de France (1978-1979). São Paulo: Martins Fontes, 2008.

GÓMEZ-ÍÑ̃IGUEZ, C. et alli. Análisis conceptual del término vigilancia desde principios del S. XX hasta la actualidad: uma perspectiva histórica. Revista de Historia de la Psicologia. Vol. 20, nº 3-4, pp. 415-428, 1999.

IZQUIERDO, Iván. Memória. Porto Alegre: Artmed, 2002.

KASTRUP, Virgínia. A invenção de si e do mundo: uma introdução do tempo e do coletivo no estudo da cognição. Belo Horizonte: Autêntica, 2007.

MIALET, Jean-Paul. L'attention. Paris: Presses Universitaires de France, 1999.

PARASURAMAN, Raja. Varieties of Attention. London: Academic Press, 1984.

ROLLS, Edmund T. Memory, Attention and Decision-Making. Oxford: Oxford University Press, 2008.

SIMONDON, Gilbert. Du mode d'existence des objets techniques. Paris: Aubier, 1989.

VIDAL JUNIOR, I. F. Atenção como transdução: notas sobre estética e política. Entre.Meios, v. 8, Rio de Janeiro: PUC-Rio, 2011. 